\title{
It's My Campaign I'll Cry if I Want to: How and When Campaigns Use Emotional Appeals
}

\author{
Travis N. Ridout \\ Assistant Professor, Political Science \\ Washington State University \\ 816 Johnson Tower, Troy Lane \\ Pullman WA 99164-4880 \\ tnridout@wsu.edu \\ Kathleen Searles \\ PhD Student, Political Science \\ Washington State University \\ 722 Johnson Tower, Troy Lane \\ Pullman WA 9914-4880 \\ ksearles@wsu.edu
}

March 3, 2009

\begin{abstract}
Recent research in the arena of campaign advertising suggests that emotional appeals can influence political attitudes, electoral choices and decision-making processes (Brader 2006; Marcus, Neuman and MacKuen 2000; Redlawsk, Civettini and Lau 2007). Yet is there any evidence that candidates use emotional appeals strategically during campaigns? Is there a pattern to their use? For instance, are fear appeals used primarily late in the campaign by trailing candidates in order to get voters to rethink their choices? And are enthusiasm appeals more common early on in order to shore up a candidate's base? In this research we develop a theory that explains when candidates use certain emotional appeals (e.g., anger, enthusiasm, fear and compassion) and which types of candidates are most likely to do so. We then test these ideas using campaign advertising data from several U.S. Senate races from 2004. Our research thus provides a link between research on campaign decision-making-here the decision to "go emotional" - and research focusing on the effects of emotional appeals on voters.
\end{abstract}

This paper was prepared for presentation at the annual meeting of the Western Political Science Association, Vancouver, British Columbia, March 19-21, 2009. 


\section{It's My Campaign I'll Cry if I Want to: How and When Campaigns Use Emotional Appeals}

There is little question that campaigns invoke emotions. Today's campaign managers must craft television advertisements that not only convey a message but simultaneously resonate with voters (Brader 2006). In the 2004 presidential race, advertisements used ominous imagery such as wolves to tap in to voters' anxieties about national security and the war in Iraq. Appeals to fear were again used in the 2008 presidential race as both major political candidates aired advertisements that questioned the ability of their challenger to deal with an economic or security crisis.

Increasingly, political scientists have recognized that both substantive and emotional content are important in understanding the effects of campaign advertising on voters. The campaign advertising literature has embraced two main approaches for studying emotional appeals (Weber 2007): emotional valence (positive versus negative advertising), and the effects of enthusiasm and anxiety. More recently, scholars have parceled out the effects of discrete emotions such as anger, fear, hope, and sadness on political participation (Bodenhausen, Sheppard and Kramer 1994; Weber 2007; Valentino, Gregorwicz and Groenendyk 2007; Valentino, Hutchings, Gregorwicz, Groenendyk and Brader 2006; Brader and Corrigan 2006). By focusing on the effects of these emotional appeals on individual voters, these approaches assume that campaigns attempt to manipulate voter emotions purposefully. If that is the case, then we ought to be able to find a systematic pattern in the use of such appeals. That is the goal of this paper: explaining which candidates use which emotional appeals in their advertising and when.

First, we develop a theory that explains when candidates use certain emotional appeals (e.g., anger, enthusiasm, fear and compassion) and which types of candidates are most likely to use them. We then test these ideas using campaign advertising data from several U.S. Senate races from 2006. Our research thus provides a link between research on campaign decisionmaking — here the decision to "go emotional"-and research focusing on the effects of emotional appeals on voters. In doing so we offer a couple of unique contributions. First, we are able to speak beyond the effects of emotional appeals on individuals and address how electoral conditions and candidate characteristics influence a campaign's decision to go emotional. Second, we add to the mounting evidence that discrete emotions produce distinct behaviors (Weber 2007) by examining when and what types of emotions are invoked.

\section{Do campaigns "go emotional"?}

Emotional appeals are central to the work of political consultants (Kern 1989) and are especially important in televised political advertising (Brader 2006). While some research suggests there is a systematic pattern to the use of emotional appeals, most studies of political decision-making treat emotion as a nuisance (see Haidt 2001 for a review; Janis and Mann 1977; Marcus 2003; Sears 1993, 2000). In spite of this, an increasing number of scholars have examined the impact of emotion on behavior and attitudes (Marcus 2003; Marcus, Neuman and Mackuen 2000; Brader 2006; Redlawsk, Civettini and Lau 2007; Lodge and Taber 2005). Recent work has found evidence of a role for affect in explaining political participation (Valentino, Gregorwicz, \& Groenendyk 2007; Valentino, Hutchings, Gregorwicz, Groenendyk, and Brader 2006; Brader and Corrigan 2006), political decision-making (Marcus 2003; Weber 2007; Brader 2005, 2006), and even morality (Forgas 2006). This research has examined affect 
as a mediator or moderator of behavior (Isbell and Wyer 1999; Ottati and Isbell 1996; Storbeck and Clore 2005), as an outcome variable (Lerner and Keltner 2001), and as an independent variable (Ellsworth and Sherer 2003; Brader 2006).

Most of these studies, however, induce affect in a laboratory setting. Because of this, there is little understanding of when and under what circumstances emotional appeals are made in the real world. In our case, when and why do campaigns make the decision to invoke emotion? This would appear to be a shortcoming of the affective literature since the general public does not experience campaign advertising in a controlled environment. Knowledge of the likely conditions under which campaigns manipulate emotions in the field would shed light on existing evidence of individual-level effects of emotions. To expand this discussion, we first survey prominent social psychological perspectives on affect (Lerner and Keltner 2001; Forgas 2006; Ellsworth and Sherer 2003; Isbell 2004). We then turn to the most substantive theoretical model of political emotions, affective intelligence theory, to buoy our own hypotheses (Marcus 2000, 2003; Marcus et al. 2000; Brader 2006). ${ }^{1}$

Socio-Psychological Approaches to Affect

A theoretical discussion of affect generally begins with the assessment of an event or situation and the role of emotion thereon (Marcus 2003; Weber 2007; Forgas 2006). There is a robust debate within the field of psychology on the independence (Zajonc 1980; Isbell 2004; Lazarus 1982) versus interdependence (Winkielman and Cacioppo 2006) of affect and cognition. Despite issues of temporality, most of the literature can be organized by the researcher's focus on either the antecedents or the consequences of emotion. ${ }^{2}$

Discrete theories of emotion typically focus on the antecedents of affect (Marcus 2000). ${ }^{3}$ Cognitive appraisal theory, one of the more robust discrete models, argues that different combinations of appraisals, which contain social, psychological, and physiologically processes, elicit discrete emotional responses (Weber 2007). An event that an individual perceives as unexpected and undesired, for example, is associated with appraisals of control. This appraisal invokes an angry response that may result in risky behaviors (Lerner and Keltner 2001). Weber (2007) tests this model and finds that appeals to anger increase personal efficacy, while appeals to sadness or fear decrease personal efficacy.

Similarly, attribution theory focuses on the attribution processes that precede emotion. Attribution theorists argue that emotion is the consequence of an evaluation of a stimulus based on three dimensions: control, responsibility, and certainty (Ellsworth and Sherer 2003; Scherer 2001; Roseman and Smith 2001). For instance, if individuals appraise a negative situation as beyond control, they will likely experience fear, whereas, if individuals perceive a negative situation that is under their control, they will likely experience anger.

Further work on the "appraisal tendency effect" has focused on the interdependence of emotion and cognition (Keltner et al. 1993; Lerner and Keltner 2001; Lerner, Gonzalez et al.

\footnotetext{
${ }^{1}$ The valence-arousal model, a competing theoretical framework, suffers from both conceptual and measurement issues (Marcus 2000) as well as its inability to account for aversion (Marcus et al. 2000), and thus we focus on affective intelligence theory.

${ }^{2}$ The controversy over the primacy of emotion (Zajonc 1980) versus the primacy of cognition (Lazarus 1982) has quelled in the wake of neuroscientific findings which support the interdependence of the two (Winkielman and Cacioppo 2006).

${ }^{3}$ Until recently cognitive appraisal theorists have also argued for the primacy and independence of cognition. See Forgas (2006) for a review.
} 
2003). This effect suggests that fear engages an appraisal process that elicits risk-avoidance behaviors, whereas anger elicits risky behavior. For example, fear might compel voters to engage in a search for information that reduces the risk involved with candidate choice, whereas anger might elevate voters' senses of commitment (despite risk of electoral loss) by compelling them to volunteer for their favored candidates.

Taking a different tack, mood theorists have focused largely on the behavioral consequences of emotion in the affect-as-information literature (Isbell 2004; Forgas 2006). Findings from this literature suggest that affective states provide cues regarding the inherent value of an action or an event (Clore and Storbeck 2006). Moreover, these affective states influence judgment and action tendencies (Schwarz and Clore 1983; Isbell 2004; Otatti and Isbell 1996). Isbell (2004) finds that both angry and happy moods confirm an individual's status quo, while Bodenhausen and colleagues (1994) found that these same moods caused participants to rely on stereotypes when processing information more than sad participants.

Affective Intelligence Theory

Affective intelligence theory, the dominant affective theoretical model in political science as set forth by Marcus et al. (2000; Marcus and Mackuen 1993), avoids the controversies and limitations that plague other approaches by taking a behavioral systems approach (Marcus 2000; McDermott 2004) to understanding the role of emotion in information processing and political participation. ${ }^{4}$ Building upon extensive biological work, this approach categorizes emotional responses by their relation to one of two systems, the disposition system and the surveillance system, both of which give information to individuals regarding their current situations. The former system cues the processor to rely on habits, while the latter encourages an increased attention to stimuli (Marcus, Neuman and Mackuen 2000; Marcus and Mackuen 1993).

The disposition system identifies successful behaviors, relates these previously learned attachments (referred to as symbols by others, see Sears 1993) to political decisions and invokes corresponding emotions from one of two dimensions: happiness-sadness (e.g., hope, enthusiasm, pride, sadness), and aversion (e.g., contempt, hatred, anger). ${ }^{5}$ When using the disposition system, individuals will rely on routine, or in a political situation, partisanship (Marcus, Mackuen, Neuman and Keele 2007). ${ }^{6}$ Although not much research has focused on the specific political effects of the emotions associated with the disposition system, anger has been known to increase individual commitment to a candidate (despite risks) by either money or time donation (Izard 1991; Lerner and Keltner 2001; Huddy, Feldman and Cassese 2007; Weber 2007). Moreover, Schnur (2007) claims that compassion appeals are used to solidify candidate image and attract core supporters.

Unlike the familiarity of the disposition system, the surveillance system focuses individual attentions on the unique and, by doing so, warns of potentially threatening stimuli. To allocate appropriate attention to unfamiliar circumstances, the surveillance system summons

\footnotetext{
${ }^{4}$ Note that while Redlawsk, Civettini and Lau (2007) argue that affective primacy is central to the theory of affective intelligence, in the same volume, Marcus and colleagues claim that because of their conceptualization of cognition, the two processes are interdependent and context-specific.

${ }^{5}$ Affective intelligence theory, unlike valence-arousal theory, argues that what people do is largely driven by associative, not declarative memory (Marcus 2000; Marcus et al. 2007).

${ }^{6}$ Marcus and colleagues (2007) find that the disposition system modulates partisanship and ideology in the same manner.
} 
emotions that fall along an anxious-calm continuum. In addition to assigning heightened attention, in this state individuals will shed partisan habits and possibly engage in political learning. Thus, scholars have found anxiety to promote the search for information, to increase attention paid to campaigns, and to increase interest in the outcome of a race (Marcus and Mackuen 1993; Marcus et al. 2000; Rudolph, Gangl and Stevens 2000). Furthermore, in an expansive discussion on the effects of anxiety, Marcus and colleagues (2007) find a direct relationship between increased anxiety and increased partisan defection. This is supported by research which finds that individuals experiencing anxiety are likely to increase their assessments of risk when contemplating action, while the opposite is true for individuals experiencing anger (Huddy, Feldman and Cassese 2007). For example, individuals feeling anxious about a race may see greater risk in relying on partisan cues.

Based on affective intelligence theory's framework we can sketch some rough expectations regarding a campaign's strategic choice of using an emotional appeal. First, we expect campaigns to make enthusiasm, pride, compassion and anger appeals to shore up partisan support and thus to maintain the status quo. Given research showing the relationship between enthusiasm and turnout (Marcus and MacKuen 1993), we also expect the use of enthusiasm appeals to get out the vote. Finally, we expect campaigns to make fear appeals to release voters from their partisan anchors. ${ }^{7}$

\section{Which Candidates “Go Emotional”?}

Research indicates that there is significant variation in behavioral effects of discrete emotions (Lerner and Keltner 2001; Weber 2007), and the types of emotions invoked by campaigns are also likely to depend on the characteristics of the candidate, the circumstances of the race, and the desired behavioral outcome (Skaperdas and Grofman 1995; Marcus 2000; Brader 2006). For example, fear-evoking advertisements are believed to be favored in competitive races (Brader 2005). Schnur (2007), speaking from direct experience in the campaign trenches, argues that candidates strategically select emotional appeals based on two objectives: enhancing or maintaining their position in the race, and targeting the audiences needed to accomplish the first objective. In the same volume, Mackuen et al. (2007) use different language to echo similar sentiments in their discussion on the importance of political geography in affective decision-making.

Based on the theory and findings outlined above, we expect that campaigns will use emotions associated with the disposition system (enthusiasm, anger, compassion) to appeal to existing supporters and their base. Additionally, we expect that campaigns will use emotions associated with the surveillance system (fear) to influence undecided voters and make their opponent's supporters rethink their decisions.

More specifically, theory suggests that:

H1: Leading candidates should be more likely than their opponents to use emotions associated with the disposition system (enthusiasm, compassion and anger) to maintain the status quo and shut down processing.

$\mathrm{H} 2$ : Trailing candidates should be more likely than their opponents to use emotions associated with the surveillance system (fear) to encourage political learning and upset the status quo.

\footnotetext{
${ }^{7}$ For the sake of conceptual clarity, note that similarly to Marcus and colleagues, we use fear and anxiety interchangeably.
} 
Next we turn our attention to the timing of emotional appeals.

\section{When do campaigns "go emotional"?}

All campaigns use emotional appeals, but it is likely that their patterns of use vary depending on the circumstances of the race. Similar to the varying conditions under which campaigns will "go negative" (Haynes and Rhine 1998; Ansolabehere and Iyengar 1995; Skaperdas and Grofman 1995), the use of emotional appeals in campaign advertising depends on the electoral climate (Abelson et al. 1982; Marcus et al. 2000; Marcus 2000; Brader 2005). Based on these suggestions and expectations derived from affective intelligence theory we test the following:

H3: Enthusiasm appeals are likely to be used by all candidates early in a campaign to shore up partisan support.

H4: Enthusiasm appeals are also likely to be used very late in a campaign to encourage existing supporters to show up at the polls.

H5: Compassion appeals are likely to be used by all candidates early in a campaign to develop a candidate's image and shore up partisan support.

H6: Fear appeals are likely to be used late in a campaign, especially by challengers, to encourage political learning among undecided voters.

Finally, although anger appeals should produce the same behavioral outcomes as pride, enthusiasm or compassion appeals, they may not be used as frequently, or at the same time, because campaign managers also consider the tone of an advertisement in choosing whether and when to air it. Namely, airing negative ads comes with the risk of a backlash (Damore 2002), and thus candidates should be unlikely to use them at the beginning of a race when they still have time to make up ground using positive advertising. Thus, given that the bulk of anger appeals are negative (as we will show in the next section), we expect that:

H7: When anger appeals are used, especially by incumbents, they should be used toward the end of a campaign.

\section{Data and Methods}

To examine when and which types of candidates use certain emotional appeals, we examined advertising patterns from 26 different U.S. Senate races from the year $2004{ }^{8}$ To measure the advertising environment, we employed ad tracking data obtained from the Wisconsin Advertising Project. ${ }^{9}$ These data report the date, sponsor and location (media market) of each ad airing in the top 100 markets, and we supplemented the project's coding with coding of our own about the emotions elicited from each ad. Two coders were asked to report whether each ad was intended to produce each of five emotions: anger, fear, enthusiasm, pride and compassion. These were the five emotions that Brader (2006) found most frequently in political ads in the 2000 campaign. Coders were asked specifically, "Was the sponsor of this ad attempting to elicit [insert emotion]?" The objective of this question was not to tap the

\footnotetext{
${ }^{8}$ Given the unique run-off elections that Louisiana holds, we eliminated the Louisiana Senate race from our analysis. We also had to eliminate Senate races in states not covered by one of the top 100 media markets, which included Alaska, Idaho, Hawaii, North Dakota and South Dakota. Even though our data covered Alabama and Utah, there were no advertisements aired in the highly uncompetitive Senate races in those states.

${ }^{9}$ Data are available at http://www.polisci.wisc.edu/tvadvertising.
} 
emotional response of the coder, but to allow the coder to judge independently the ad maker's goal in designing the message. Coders could respond by indicating the ad contained "no appeal" to the emotion, "some appeal," or a "strong appeal." In order to reduce ambiguity in whether an emotion was present or not, we focused on only those appeals that coders deemed "strong."

To assess the reliability of the coding, we had 10 additional coders assess up to 80 random ads on each of the five emotions. In general, inter-coder reliability was quite high. For fear and anger, Pearson correlations on the three-category coding ranged between a low of 0.55 to a high of 0.82. For enthusiasm, correlations were even higher, ranging between 0.65 and 0.81 . Coders, however, had significantly more trouble assessing the presence of compassion appeals. Across the 10 coders, the average correlation was just below .40, and that gives us some pause in interpreting the results for the use of compassion appeals.

Table 1 shows the correlations between each of the five emotions examined-and their correlations with a traditional three-fold measure of tone (positive, contrast and negative). ${ }^{10}$ The first thing to note is that the use of any emotional appeal is positively correlated with the use of any other emotional appeal, which suggests that some ads are more likely to contain emotional appeals - regardless of the emotion - and others are not. The magnitude of the correlations varies considerably, however, ranging from .17 between enthusiasm and fear to .71 between pride and enthusiasm. Given this high correlation — and the fact that in almost 90 percent of the cases where coders identified enthusiasm they also reported the presence of a pride appeal—we decided to combine those two categories into one.

\section{[Table 1 Here]}

It is also worth noting that fear and anger ads are not synonymous with negative ads, nor are pride and enthusiasm synonymous with positive ads. Nonetheless, there are some relationships between the emotions evoked by advertising and their tone. Anger ads, for instance, tended not to be positive (only 18 percent were), and enthusiasm ads tended to be positive ( 88 percent were). Still, one can find positive, contrast and negative ads that elicit each and every emotional appeal.

For our statistical analyses, we considered all ads aired by Democratic or Republican candidates in each of the races examined between June 1, 2004, and Election Day, November 2. We created an indicator variable of whether each Senate candidate in each state aired an ad that made a strong appeal to each of the emotions examined on each day. These indicators serve as dependent variables in the statistical models that we estimated, one each for anger ads, fear ads, enthusiasm/pride ads and compassion ads.

Independent variables in models included:

Democrat: Although we did not have strong theory to suggest the candidates of one party might be more or less likely to use certain appeals, we did wonder whether candidates would play to their strengths as issue ownership theory (Petrocik 1996) might suggest. Thus, Republicans might be more likely to use fear appeals (especially in light of the events of September 11, 2001), and Democrats might be more likely to use compassion appeals. This

\footnotetext{
${ }^{10}$ Coders at the Wisconsin Advertising Project were asked: In your judgment, is the primary purpose of the ad to promote a specific candidate ("In his distinguished career, Senator Jones has brought millions of dollars home. We need Senator Jones"), to attack a candidate ("In his long years in Washington, Senator Jones has raised your taxes over and over. We can't afford 6 more years of Jones.") or to contrast the candidates ("While Senator Jones has been raising your taxes, Representative Smith has been cutting them.")?
} 
party indicator variable was coded 1 if the candidate was a Democrat, 0 if the candidate was a Republican.

Female. This indicator was coded 1 if the candidate was a woman, 0 if the candidate was a man. Again, issue ownership theory might suggest that candidates would play to strengths, that is, that women might be more likely to air ads with compassion appeals to play to gender stereotypes (Hernson, Lay and Stokes 2003). But others have found that women use "tough" language in their advertising in order to counteract gender stereotypes (Sapiro and Walsh 2002).

Month Indicators. In order to test some of our expectations for the timing of the airing of certain appeals, we created a series of dummy variables, one each for June, July, August, and September, which left October and the first two days of November as the baseline.

Days to Election: In another attempt to account for timing, we created this counter variable, which took the value of 0 on Election Day, 1 the day before the election and so on.

Competitiveness: We wanted to test whether candidates might be more likely to use certain types of appeals, especially anxiety appeals that might make voters rethink their choices, when the race was close. We therefore included a measure of the race's competitiveness taken from Congressional Quarterly's final pre-election risk rating. This variable was coded 0 if the race was "safe" for one candidate, coded 1 if it was favored for one candidate, coded 2 if it leaned toward one candidate and was coded 3 if it was a toss-up.

Candidate Advantage: This variable, designed to indicate by how much a candidate was leading or trailing, was calculated on the basis of the CQ risk rankings. For instance, a candidate who was safe received a score of 3, while his or her opponent received a score of -3 . A candidate who was favored received a score of 2 , while his or her opponent received a score of -2. The same logic follows for the scoring of candidates in races that were leaning. If the race was deemed a toss-up, then no candidate had an advantage, and both candidates received a score of 0 .

Count of Ads: Because some candidates had access to more resources, they were able to air more ads, and thus the likelihood that these resource-rich candidates would air an ad making a specific emotional appeal was higher. We thus included the total number of ads aired by the candidate as another variable in our models to tap available resources.

Incumbency: Finally, because we hypothesized that the behavior of incumbents and challengers might be different, we created an indicator of whether the candidate was an incumbent or not.

Because our dependent variable is dichotomous, we used a logit model to estimate the likelihood of using each appeal, and because observations within each state were not independent, we clustered on state.

\section{Results}

In order to get a better understanding of our data, we plotted each ad type as a percentage of total ads in each week of the campaign, going back to the beginning of June (Figure 1). Given the great variations week to week, it is difficult to tell a definitive story about patterns of use over time, but it does seem that anger ads were most common during the summer and immediately before the election, while fear-focused ads were more common closer to Election Day. Compassion ads seemed to peak about 12 weeks before the election, while ads that invoked enthusiasm or pride seemed to steadily decline over the election season. Obviously, we will need the information provided by some additional analysis in order to draw some firmer conclusions. 
[Figure 1 Here]

Table 2, which shows the estimates from our four models predicting whether candidates used specific emotional appeals on each day of the race, reveals that there is a systematic pattern to the use of the emotional appeals, though the use of some is much more predictable than the use of others.

\section{[Table 2 Here]}

Our first hypotheses concerned differences between leading and trailing candidates. We hypothesized that leading candidates would be more likely to use anger, enthusiasm/pride and compassion appeals (H1), while trailing candidates would be more likely to use fear appeals (H2). Our model estimates, reported in Table 2, lend only some support to these hypotheses. Trailing candidates were significantly more likely to use fear, while leading candidates were significantly more likely to use enthusiasm/pride appeals. We found no differences, though, in candidates' likelihood of using compassion appeals, and contrary to our expectations, trailing candidates were more likely than their opponents to use anger appeals. Additionally, we had hypothesized that candidates (regardless of incumbency status) would be more likely to use enthusiasm/pride appeals (H3) and compassion appeals (H5) early in the race in order to shore up their support, though we expected an uptick in enthusiasm ads late in the campaign as well in order to draw voters to the polls (H4). There is limited support for this first expectation, for while the signs on the month indicators are positive, indicating that enthusiasm appeals are more likely in the earlier months of the campaign than in October (the omitted category), none of the coefficients was statistically significant. We find no rhyme or reason to the pattern of the use of compassion appeals. In none of the months is a compassion appeal more or less likely than in October. We also find no support for the idea that enthusiasm appeals spike close to Election Day in order to bring supporters to the polls. Although our hypothesis goes unsupported, our findings are consistent with those of Brader (2006) who likewise found no evidence that candidates use enthusiasm appeals at the end of a campaign to bring supporters to the polls. It is likely, at this point, that they are using on-the-ground GOTV efforts such as door-to-door canvassing or mailings instead of relying on television advertising.

We will address the rest of our specific hypotheses in the models that follow, which allows us to compare the behavior of incumbents and challengers. We do, however, want to make some more comments here about the patterns of use of certain appeals. First, there are party differences in the use of fear and anger appeals, with Democrats less likely than Republicans to use both types of emotional appeal. There are also gender differences, but instead of playing to type, women candidates seem to be playing against type by airing more anger and fear ads than their male opponents. Women also air fewer enthusiasm and pride ads than men.

The competitiveness of the race mattered for only one type of appeal: more competitive races are more likely to see anger appeals. Being ahead in the race also affected the likelihood of using various emotions in one's advertising. Candidates who were further ahead were less likely to use anger and fear appeals and were more likely to use enthusiasm and pride appeals. Finally, as expected, the more ads a candidate aired the more likely he or she was to use all types of emotional appeals, with the exception of compassion ads. Indeed, the use of compassion appeals was totally unpredictable. Not a single one of the independent variables affected the likelihood of airing a compassion ad.

Our final hypotheses concern when certain types of appeals are more likely to be used by certain types of candidates (i.e., incumbents or challengers). In order to address these 
expectations, we estimated separate models for incumbents and challengers. Because this reduced the size of our sample, we replaced our timing measures (the series of month indicator variables) with a single variable, the number of days to elections. We also dropped the female indicator given the lack of variation on this variable. And because we were estimating separate models for incumbents and challengers, it was necessary that we exclude the incumbent indicator from our models.

The estimates from eight separate models shown in Table 3 speak to the timing of the use of emotional appeals by incumbency status. We had expected that candidates, especially challengers, would use fear appeals late in the campaign in order to encourage political learning among undecided voters (H6), shaking up the race, and that is what we find. The further from Election Day, the less likely challengers are to use fear appeals. By contrast, the time from Election Day has no impact on the likelihood of an incumbent using a fear appeal. Our final hypothesis was that anger appeals, which should be used especially by incumbents, will be used toward the end of the campaign as the use of negativity (which anger ads often are) presents the risk of a backlash (H7). The estimates show that anger ads are indeed used later in the campaign, and this holds true for both incumbents and challengers.

Our results here, which are broken down by incumbency status, confirm our findings above that enthusiasm/pride ads were more likely used earlier in the campaign, and this holds true for both incumbents and challengers. Again, however, the use of compassion appeals is largely unpredictable regardless of incumbency status. The only significant finding with regard to compassion appeals is that Democratic challengers are more likely to use them than Republican challengers.

\section{Discussion and Conclusion}

Our research has shown that there are some systematic patterns to the use of specific emotional appeals in political campaigns, though the use of some appeals, such as anger, is much more predictable than the use of other appeals, such as compassion. Our expectations that leading candidates would be more likely to focus on enthusiasm appeals, while trailing candidates would focus on fear appeals, were also supported by our analyses. One reason for our inability to predict the use of compassion appeals may be the difficulty our coders had in agreeing which ads appealed to compassion and which did not. Given the low reliability of our measure of compassion, it is not surprising that we had difficulty predicting its use.

Our hypotheses with respect to anger also did not fare well. Although our expectation that anger appeals would be used later in a campaign was correct, our thinking that leading candidates would be more likely to use them than trailing candidates was not correct. In fact, the reverse was true. Why did we do such a poor job in predicting who would use anger appeals? One reason may be that the idea that anger shuts down processing is not correct; anger may act similarly to fear. Indeed, Brader (2006) combines the two emotions into one in his experimental research. Another reason may be that political professionals do not know as much as psychologists and assume, incorrectly, that anger works like fear does in inducing information processing. They may be thinking more in terms of valence (positive or negative) as opposed to thinking about specific emotions. Finally, there may be some risks associated with the use of anger appeals that are not present with the use of enthusiasm, pride or compassion appeals, given that anger appeals are typically negative ones that discuss an opponent. Perhaps voters are willing to put up with ads that make them angry in the few weeks before they vote- - such ads 
may be expected at this time-but negative appeals to anger may turn them off early in the campaign season.

In sum, while our specific-emotions model worked fairly well in predicting the use of fear and enthusiasm/pride appeals, it did not work so well in predicting the use of compassion appeals or anger appeals. Given our pattern of results, we think a valence model, one focused on positive and negative as opposed to specific positive or negative emotions, may do just as well as explaining the pattern of the use advertising appeals as a specific-emotions model, if not better. Such a model, which would incorporate the risk associated with using negative appeals, could help to explain why anger ads and fear ads (at least among challengers) are used more frequently closer to Election Day.

That said, we believe our research contributes much to the understanding of the use of emotional appeals in the real world of political campaigns. Indeed, while we have only so far tapped the surface by examining which candidates use which appeals when, we believe that taking the next step-examining how such appeals work in the real world of campaigns-is a worthwhile endeavor. For while theorists of emotions may find that appeals work as hypothesized in tightly controlled experimental settings with ads carefully designed to appeal to specific emotions, they may not work as such in the real world, where the ads may not be so blatant and where citizens come to the advertisement not as blank slates but as people with previous knowledge about the candidates. 
Figure 1: Use of Appeals Over Time
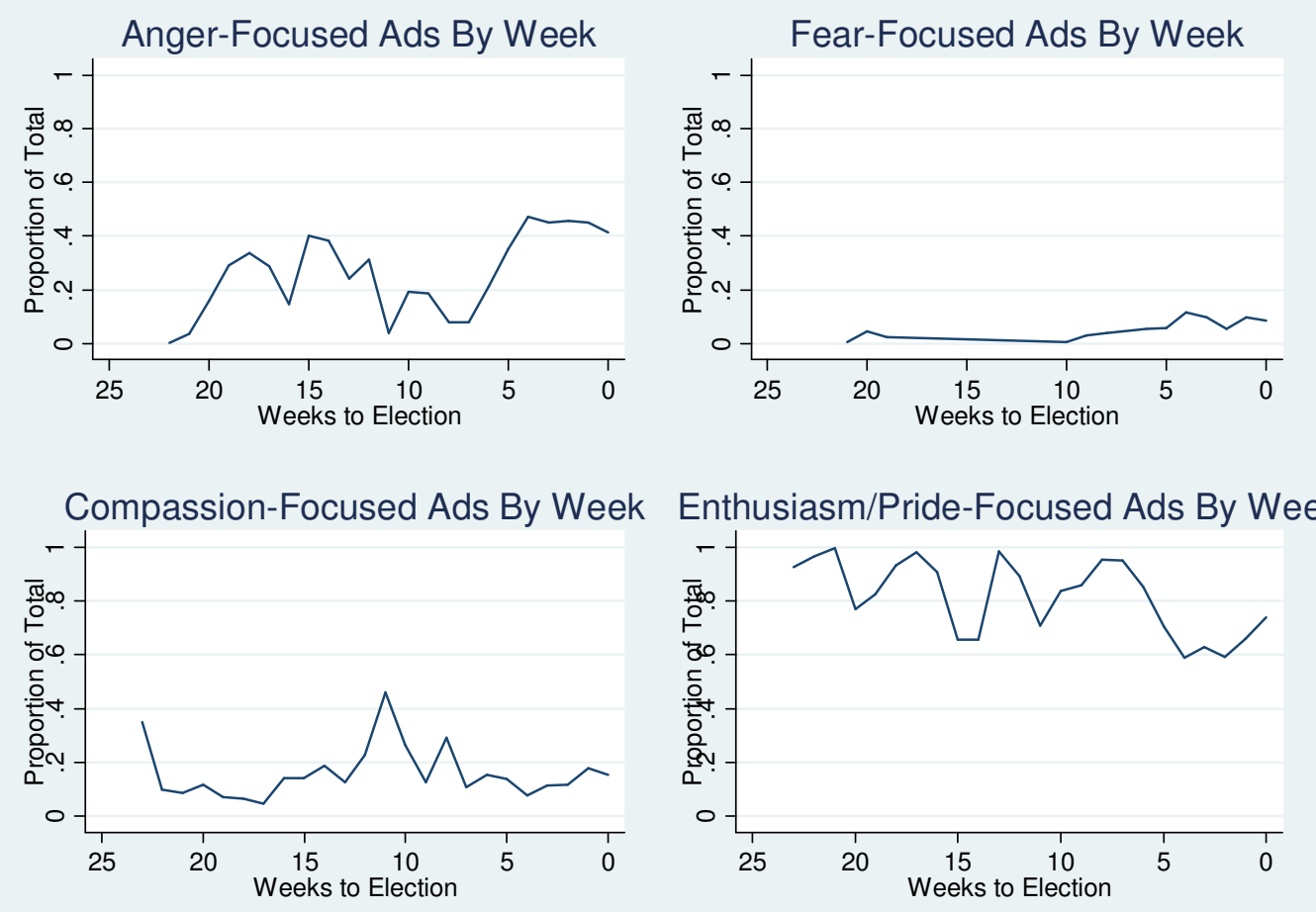
Table 1: Correlations Between Use of Emotional Appeals and Tone

$\begin{array}{lccccccc} & \text { Fear } & \text { Anger } & \text { Enthus. } & \text { Pride } & \text { Compas. } & \text { Negative } & \text { Contrast } \\ \text { Fear } & 1.00 & & & & & & \\ \text { Anger } & 0.20 & 1.00 & & & & & \\ \text { Enthusiasm } & -0.13 & -0.37 & 1.00 & & & & \\ \text { Pride } & -0.17 & -0.38 & 0.07 & 1.00 & & & \\ \text { Compassion } & 0.01 & -0.06 & -0.05 & -0.08 & 1.00 & & \\ \text { Negative } & 0.17 & 0.40 & -0.26 & -0.39 & 0.01 & 1.00 & \\ \text { Contrast } & 0.12 & 0.47 & -0.25 & -0.11 & -0.09 & -0.19 & 1.00 \\ \text { Positive } & -0.21 & -0.67 & 0.39 & 0.35 & 0.07 & -0.49 & -0.77\end{array}$


Table 2: Predictors of Use of Each Emotional Appeal

\begin{tabular}{lcccccccc} 
& \multicolumn{2}{c}{ Anger } & \multicolumn{2}{c}{ Fear } & \multicolumn{3}{c}{ Enthusiasm/Pride } & \multicolumn{2}{c}{ Compassion } \\
Democrat & $\mathbf{- 1 . 3 4 7}$ & 0.337 & $\mathbf{- 2 . 7 5 5}$ & 0.562 & 0.475 & 0.667 & 0.181 & 0.319 \\
Female & $\mathbf{1 . 3 6 2}$ & 0.466 & $\mathbf{2 . 8 2 1}$ & 0.783 & $\mathbf{- 1 . 0 4 5}$ & 0.551 & 0.766 & 0.580 \\
June & $\mathbf{- 1 . 8 6 0}$ & 0.604 & $\mathbf{- 1 . 0 6 6}$ & 0.610 & 0.958 & 0.868 & -0.808 & 0.866 \\
July & $\mathbf{- 1 . 4 2 4}$ & 0.562 & & & 1.166 & 0.616 & -0.100 & 0.482 \\
August & $\mathbf{- 2 . 4 5 9}$ & 0.638 & -1.955 & 1.332 & 1.818 & 1.127 & 0.444 & 0.561 \\
September & $\mathbf{- 1 . 2 7 0}$ & 0.274 & -0.693 & 0.527 & 0.679 & 0.521 & -0.228 & 0.271 \\
Incumbent & $\mathbf{- 0 . 6 4 7}$ & 0.395 & 0.494 & 0.565 & -0.197 & 0.446 & -0.246 & 0.606 \\
Competitiveness & $\mathbf{0 . 2 3 1}$ & 0.173 & 0.326 & 0.305 & -0.082 & 0.160 & 0.291 & 0.261 \\
Advantage & $\mathbf{- 0 . 3 7 7}$ & 0.075 & $\mathbf{- 0 . 2 2 0}$ & 0.105 & $\mathbf{0 . 3 8 1}$ & 0.107 & 0.108 & 0.128 \\
Count of Ads & $\mathbf{0 . 0 1 3}$ & 0.002 & $\mathbf{0 . 0 0 5}$ & 0.001 & $\mathbf{0 . 0 0 7}$ & 0.002 & $\mathbf{0 . 0 0 5}$ & 0.003 \\
Constant & -0.085 & 0.399 & $\mathbf{- 2 . 3 4 7}$ & 0.751 & $\mathbf{1 . 4 7 7}$ & 0.451 & $\mathbf{- 1 . 9 0 8}$ & 0.575 \\
& & & & & & & 2558 & \\
N & 2558 & & 2314 & & 2558 & & & \\
Model Chi-square & $169.43(\mathrm{p}<.0001)$ & $68.79(\mathrm{p}<.0001)$ & $51.22(\mathrm{p}<.0001)$ & $39.77(\mathrm{p}<.0001)$
\end{tabular}

Bold-faced entries indicate significance at the .10 level. 
Table 3: Predictors of Use of Each Emotional Appeal by Incumbency Status

Incumbents

\begin{tabular}{|c|c|c|c|c|c|c|c|c|}
\hline \multirow[b]{2}{*}{ Democrat } & \multicolumn{2}{|c|}{ Anger } & \multicolumn{2}{|l|}{ Fear } & \multicolumn{2}{|c|}{ Enthusiasm/Pride } & \multicolumn{2}{|c|}{ Compassion } \\
\hline & -1.578 & 0.937 & -0.438 & 0.923 & -0.131 & 0.768 & -0.079 & 0.827 \\
\hline Days to Election & -0.040 & 0.010 & -0.005 & 0.010 & 0.036 & 0.008 & -0.001 & 0.007 \\
\hline Competitiveness & 1.648 & 0.963 & 1.525 & 0.639 & -1.189 & 0.682 & -0.223 & 0.683 \\
\hline Count of Ads & 0.009 & 0.003 & 0.005 & 0.002 & 0.010 & 0.006 & 0.005 & 0.003 \\
\hline Constant & -0.762 & 0.650 & -3.405 & 0.942 & 1.462 & 0.739 & -1.482 & 0.786 \\
\hline $\mathrm{N}$ & \multicolumn{2}{|l|}{825} & \multicolumn{2}{|l|}{825} & \multicolumn{2}{|l|}{825} & \multicolumn{2}{|l|}{825} \\
\hline Model Chi-square & \multicolumn{2}{|c|}{$43.31(\mathrm{p}<.0001)$} & \multicolumn{2}{|l|}{$70.73(\mathrm{p}<.0001)$} & \multicolumn{2}{|c|}{$22.18(\mathrm{p}<.0001)$} & \multicolumn{2}{|c|}{$2.71(\mathrm{p}=.607)$} \\
\hline \multicolumn{9}{|l|}{ Challengers } \\
\hline & \multicolumn{2}{|c|}{ Anger } & \multicolumn{2}{|l|}{ Fear } & \multicolumn{2}{|c|}{ Enthusiasm/Pride } & \multicolumn{2}{|c|}{ Compassion } \\
\hline Democrat & -0.722 & 0.357 & -0.949 & 0.541 & 0.427 & 0.628 & 0.675 & 0.399 \\
\hline Days to Election & -0.014 & 0.006 & -0.023 & 0.005 & 0.011 & 0.005 & -0.003 & 0.006 \\
\hline Competitiveness & 0.056 & 0.193 & 0.011 & 0.361 & 0.101 & 0.185 & 0.294 & 0.295 \\
\hline Count of Ads & 0.013 & 0.002 & 0.004 & 0.002 & 0.008 & 0.003 & 0.005 & 0.003 \\
\hline Constant & 0.049 & 0.542 & -1.170 & 0.665 & 0.684 & 0.597 & -1.921 & 0.644 \\
\hline $\mathrm{N}$ & \multicolumn{2}{|l|}{1,733} & \multicolumn{2}{|l|}{1,733} & \multicolumn{2}{|l|}{1,733} & \multicolumn{2}{|l|}{1,733} \\
\hline Model Chi-square & \multicolumn{2}{|c|}{$40.57(\mathrm{p}<.0001)$} & \multicolumn{2}{|l|}{$35.88(\mathrm{p}<.0001)$} & \multicolumn{2}{|c|}{$18.59(\mathrm{p}=.0009)$} & \multicolumn{2}{|c|}{$50.59(\mathrm{p}<.0001)$} \\
\hline
\end{tabular}




\section{References}

Abelson, Robert P., Donald R. Kinder, Mark D. Peters, and Susan T. Fiske. 1982. "Affective and Semantic Components in Political Person Perception." Journal of Personality and Social Psychology 42 (4): 619-30.

Ansolabehere, Stephen and Shanto Iyengar. 1995. Going Negative: How Attack Ads Shrink and Polarize the Electorate. New York: Simon \& Schuster.

Brader, Ted. 2005. "Striking a Responsive Chord: How Political Ads Motivate and Persuade Voters by Appealing to Emotions." American Journal of Political Science 49(2): 388405.

Brader, Ted. 2006. Campaigning for Hearts and Minds: How Emotional Appeals in Political Ads Work, Studies in Communication, Media, \& Public Opinion. Chicago: University of Chicago Press.

Brader, Ted and Bryce Corrigan. 2006. "How the Emotional Tenor of Ad Campaigns Affects Political Participation." Paper presented at the annual of the American Political Science Association, Philadelphia, PA.

Clore, Gerald L. and Joseph Storbeck. 2006. "Affect as information about liking, efficacy, and importance." In Joseph Forgas (Ed). Hearts and Minds: Affective influences on social cognition and behaviour. New York: Psychology Press.

Damore, David F. 2002. "Candidate Strategy and the Decision to Go Negative." Political Research Quarterly 55: 669-85.

Haynes, Audrey A. and Staci L. Rhine. 1998. "Attack Politics in Presidential Nomination Campaigns: An Examination of the Frequency and Determinants of Intermediated Negative Messages Against Opponents.” Political Research Quarterly 51: 691-721.

Herrnson, Paul S., J. Celeste Lay and Atiya Kai Stokes. 2003. “Women Running 'as Women': Candidate Gender, Campaign Issues, and Voter-Targeting Strategies.” Journal of Politics 65: 244-255.

Huddy, Leonie, Stanley Feldman and Erin Cassese. 2007. "On the Distinct Political Effects of Anxiety and Anger." In The Affect Effect, W. Russell Neuman, George E. Marcus, Ann N. Crigler and Michael Mackuen (Eds). Chicago: The University of Chicago Press.

Kern, Montague. 1989. 30-Second Politics: Political Advertising in the Eighties. New York: Praeger.

Lazarus, Richard S. 1982. "Thoughts on the Relations between Emotions and Cognition." American Physiologist 37(10): 1019-24. 
Lerner, Jennifer and Dacher Keltner. 2000. "Beyond Valence: Toward a Model of Emotion Specific Influences on Judgment \& Choice.” Cognition \& Emotion 14(4):431-53.

Lodge, Milton and Charles Taber. 2005. "Implicit Affect for Political Candidates, Parties, \& Issues: An Experimental Test of the Hot Cognition Hypothesis." Political Psychology 26(3):455-82.

Marcus, George E. 2000. "Emotions in Politics." Annual Review of Political Science 3: 221-50.

Marcus, George E. 2003. "The Psychology of Emotion \& Politics." In Oxford Handbook of Political Psychology, David Sears, Leonie Huddy, \& Richard Jervis (Eds). New York: Oxford University Press.

Marcus, George E. and Michael Mackuen. 1993. "Anxiety, Enthusiasm, and the Vote: The Emotional Underpinnings of Learning \& Involvement During Presidential Campaigns." The American Political Science Review 87 (3): 672-85.

Marcus, George E., William R. Neuman and Michael MacKuen. 2000. Affective Intelligence \& Political Judgment. Chicago: University of Chicago Press.

McDermott, Rose. 2004. "The Feeling of Rationality: The Meaning of Neuroscientific Advances for Political Science.” Perspectives on Politics 4(2):691-707.

Perloff, Richard M. and Dennis Kinsey. 1992. "Political Advertising as Seen by Consultants and Journalists." Journal of Advertising Research 32 (3): 53-60.

Petrocik, John. 1996. "Issue ownership in Presidential Elections, with a 1980 Case Study." American Journal of Political Science 40(3): 825-50.

Rudolph, T.J., Amy Gangl, and Dan Stevens. 2000. “The Effects of Efficacy and Emotions on Campaign Involvement." Journal of Politics 62(4): 1189-97.

Sapiro, Virginia and Katherine Cramer Walsh. 2002. "Doing Gender in Congressional Campaign Advertisements." Paper presented at the Annual Meeting of the International Society for Political Psychology, Berlin.

Schnur, Dan. 2007. "The Affect Effect in the Very Real World of Political Campaigns.” In The Affect Effect, William R. Neuman, George E. Marcus, Ann N. Crigler, and Michael Mackuen (Eds). Chicago: The University of Chicago Press.

Sears, David O. 1993. "Symbolic Politics: A Socio-psychologic theory." In Explorations in Political Psychology, Shanto Iyengar and William J. McGuire (Eds.). Durham, NC: Duke University Press. 
Sears, David O. 2000. "The role of affect in symbol politics." In Citizens and Politics: Perspectives from Political Psychology, John Kulunski (Ed.). New York: Cambridge University Press.

Skaperdas, Stergio, and Bernard Grofman. 1995. "Modeling Negative Campaigning." American Political Science Review 89: 49-61.

Valentino, Nicholas, Vincent Hutchings, Kristine Gregorowicz and Eric Groenendyk. 2006. Election Night's Alright For Fighting: The Participatory Impact of Negative Emotions. Paper presented at the annual of the American Political Science Association, Philadelphia, PA.

Valentino, N., Gregorowicz, K., \& Groenendyk, E.W. (2007). "Emotions, Efficacy, and Political Participation." Presented at the Annual Meeting of the International Society of Political Psychology, Portland, OR.

Zajonc, Robert B. 1980. "Feeling and Thinking: Preferences Need No Inferences." American Psychologist 35: 151-175 